\title{
Synthesis and Optical Characterization of Ag/PVA Nanocomposites Films
}

\author{
Hussein T. Salloom $^{1 *}$, Aseel S. Jasim ${ }^{1}$ and Tagreed K. Hamad ${ }^{2}$ \\ ${ }^{1}$ Al-Nahrain Nanorenewable Energy Research Center, Al-Nahrain University, Baghdad-Iraq. \\ ${ }^{2}$ Department of Physics, College of Science, Al-Nahrain University, Baghdad-Iraq. \\ *Corresponding Author: abnthamer@gmail.com.
}

\begin{abstract}
Silver- Poly vinyl alcohol Ag/ PVA nanocomposite films were prepared by casting method at room temperature with different amount of $\mathrm{AgNO}_{3}$ solution $(0.001,0.0015$, and $0.002 \mathrm{ml})$. The prepared nanocomposites were characterized using UV-VIS spectrophotometer and the optical properties were investigated in the wavelength range $300-800 \mathrm{~nm}$. The absorption peaks showed a shift towards higher wavelength with increasing $\mathrm{AgNO}_{3}$ concentration while the energy band gap and absorption edges shifted towards lower energies with the increase of $\mathrm{AgNO}_{3}$ concentration.

[DOI: $10.22401 /$ JNUS.20.4.10]
\end{abstract}

Keywords: Nanocomposite, Silver- Poly vinyl alcohol, thin films.

\section{Introduction}

Polymer-based metal nanoparticles have attracted much attention due to their possibility to combine the features of organic and inorganic materials and because the highly application range offered by these hybrid composites [1-4]. Polymer matrix has the ability to prevent both oxidation and coalescence of nanoparticles and provide long time stability [3-5]. Moreover, incorporation of metal into the polymer matrix improves the thermal stability, mechanical and electrical properties. Metal-polymer nanocomposites and especially silver PVA nanocomposites are interesting functional materials in a lot of fields due to their specific physical, mechanical and antimicrobial properties. [1-5]. PVA as the host polymer for Ag nanoparticles is advantageous due to the reducing ability of the secondary alcohol groups, its excellent film forming properties and optical transparency. There are various techniques for the synthesis of silver nanocomposites, e.g., chemical reduction, laser ablation, gamma radiation, sol-gel method, electron irradiation and photochemical methods [8]. Gautam and Ram prepared Ag/PVA nanocomposites by reduction method [1]. X-ray diffraction,UVVIS analysis, scanning electron microscopy, transmission electron microscopy and currentvoltage measurements were used to characterize these films. The X-ray diffraction analysis showed that silver metal is present in faced cubic center (fcc) crystal structure. The UV-VIS spectrum revealed a single peak at $433 \mathrm{~nm}$. These results indicate that silver nanoparticles are embedded in PVA [1]. Ghanipour and Dorranian prepared Ag/PVA films by laser ablation method with different concentration of Ag nanoparticles and studied the effect of different $\mathrm{Ag}$ nanoparticles concentrations on the structural and optical properties of $\mathrm{Ag} / \mathrm{PVA}$ nanocomposite thin films using X-ray diffraction and UV-VIS spectroscopy. Results showed remarkable enhancement in crystallinity of the films by adding silver nanoparticles to PVA. Optical energy band gaps of the samples are decreased with increasing the concentrations of silver nanoparticles [3]. Yunus et al. prepared silver/PVA nanocomposite by using quick precipitation method and using hydrazine as a reduction agent. The samples were characterized by (XRD), (UV-VIS), (TEM) and Z-scan technique were carried out to characterize nonlinear optical properties. The UV-VIS results showed that the prepared nanocomposites show surface plasmon resonance in wavelength range 400-430 nm and it goes to higher wavelength by increasing the amount of reduction agent [9].

In this research Ag- PVA nanocomposite is prepared through the in-situ thermal reduction in the solution stage of the reaction mixture. The polymer prepared in the first step and then metal ions entered into polymer by using silver nitrate $\mathrm{AgNO}_{3}$ solution with different concentrations. Silver ions reduced to zero valent by heating. Thin films with thickness $60 \mu \mathrm{m}$ have been prepared by solution casting method. 


\section{Materials and Methods}

$\mathrm{AgNO}_{3}$ and PVA are used without further purification. $\mathrm{AgNO}_{3}$ solution of $1 \mathrm{~mol} / \mathrm{L}$ was first prepared by dissolving $\mathrm{AgNO} 3$ powder in distilled water. The mixture is stirred at room temperature. PVA solution is prepared by dissolving $3 \mathrm{~g}$ in $100 \mathrm{ml}$ of distilled water, the mixture was magnetically stirred at (60-70) $\mathrm{C}^{\circ}$ for $3 \mathrm{hrs}$. To each $10 \mathrm{ml}$ of PVA solution, different amount $(0.001,0.0015$, and 0.002$) \mathrm{ml}$ of $\mathrm{AgNO}_{3}$ solution was add while keeping temperature, annealing time and PVA weight $\%$ constant. The specimens are labeled as $\mathrm{S}_{1}$, $\mathrm{S}_{2}$ and $\mathrm{S}_{3}$. The heating along with stirring was continued until a brown viscous solution was obtained. The color change indicates the formation of PVA stabilized silver colloid. The reduction of silver ions from silver nitrate by the hydroxy groups of PVA polymer results in the formation of PVA capped silver nanoparticles. Then the solutions were casted on a petri dish and left for (3) days at room temperature to solidify. The films thickness were about $60 \mathrm{um}$. The thickness of films were controlled by casting the same amount of materials onto the same glass Pitri dish size.

The optical constants of Ag/ PVA nanocomposites were calculated by using SPUV-26 UV-VIS double beam spectrophotometer in the wavelength range 300-800 nm. Optical constants such as refractive index $(\mathrm{n})$, extinction coefficient $(\mathrm{k})$, dielectric constants $(\varepsilon)$ were determined by using the fundamental relations of absorbance (A), transmittance (T) and reflectance (R) respectively. The reflection $(\mathrm{R})$ can be calculated from the values of absorbance and transmission [10]

$$
R=1-A-T .
$$

The optical absorption coefficient $\alpha$ can be represented by Lambert-Beer law [11]:

$$
\alpha=2.303 \mathrm{~A} / \mathrm{t}
$$

where $\mathrm{A}$ : is the absorbance and $\mathrm{t}$ : is the sample thickness in $(\mathrm{cm})$.

The optical band gap can be determined by Tauc's plot $[7,11]$, using frequency dependent absorption coefficient that given by:

$$
\alpha h v=B\left(h v-E_{o p}\right)^{n}
$$

$\alpha$ is the absorption coefficient, B is the parameter that depends on the inter band transition probability, $h v$ is the incident photon energy, Eg is the optical band gap and (n) is an index characterizing the nature of the electronic transitions causing the optical absorption. (n) can take values $1 / 2,3 / 2,2$, and 3 for direct allowed, direct forbidden, indirect allowed and indirect forbidden transitions, respectively

The extinction coefficient can be calculated from the relation [12]:

$$
\mathrm{k}=\alpha \lambda / 4 \pi
$$

where $(\alpha)$ is the absorption coefficient and $(\lambda)$ is the wavelength

Refractive index is giving by the following equation [13]

$$
n=\left(\frac{1+R}{1-R}\right)+\sqrt{\frac{4 R}{(1-R)^{2}}-k}
$$

The dielectric constant $(\varepsilon)$ is divided into real part $\left(\varepsilon_{\mathrm{r}}\right)$ and imaginary part $\left(\varepsilon_{\mathrm{i}}\right)$, and it can be calculated by using the equation: [14]

$$
\varepsilon=\varepsilon_{\mathrm{i}}+\mathrm{i} \varepsilon_{\mathrm{i}}
$$

The real $\left(\varepsilon_{\mathrm{r}}\right)$ and imaginary $\left(\varepsilon_{\mathrm{i}}\right)$ parts of the dielectric constant are calculated by using [15, 16]:

$$
\begin{aligned}
& \varepsilon_{\mathrm{r}}=\mathrm{n}_{2}-\mathrm{k}_{2} \\
& \varepsilon_{\mathrm{i}}=2 \mathrm{nk} \ldots \ldots
\end{aligned}
$$

The optic al conductivity can be calculated by using the absorption coefficient (a), and the refractive index (n) using the following relation $[17,18]$ :

$$
\sigma=\frac{\alpha \mathrm{nc}}{4 \pi} \text {. }
$$

where (c) is the velocity of light in the space.

\section{Results and Discussion}

The variation of absorbance (A) and transmittance (T) as a function of wavelength of pure PVA and Ag/ PVA nanocomposites at different concentrations are shown in Fig.(1). and Fig.(2). It can be seen from Fig. (1), the pure PVA sample has a nearly zero absorbance in the visible region because it is a colorless polymer and show no bands in the range of measurement $[3,19]$, it is also found that the 
absorption of all prepared nanocomposites thin films increase with the increase of $\mathrm{AgNO}_{3}$ concentration which indicate that higher concentration generate higher number of $\mathrm{Ag}$ nanoparticles. The absorption peak above $400 \mathrm{~nm}$ indicates the formation of silver nanoparticles [1,15]. As the concentration increases there is not only increase in the absorption peak spectra but a red shift in the surface plasmon resonance (SPR) wavelength $[9,20]$. This behavior is due to strong interaction of the silver nanoparticles with light that occurs when the conduction electrons on the metal surface undergo collective oscillation. Moreover SPR wavelength can be tuned by changing the particle size and the local refractive index. [9,21]

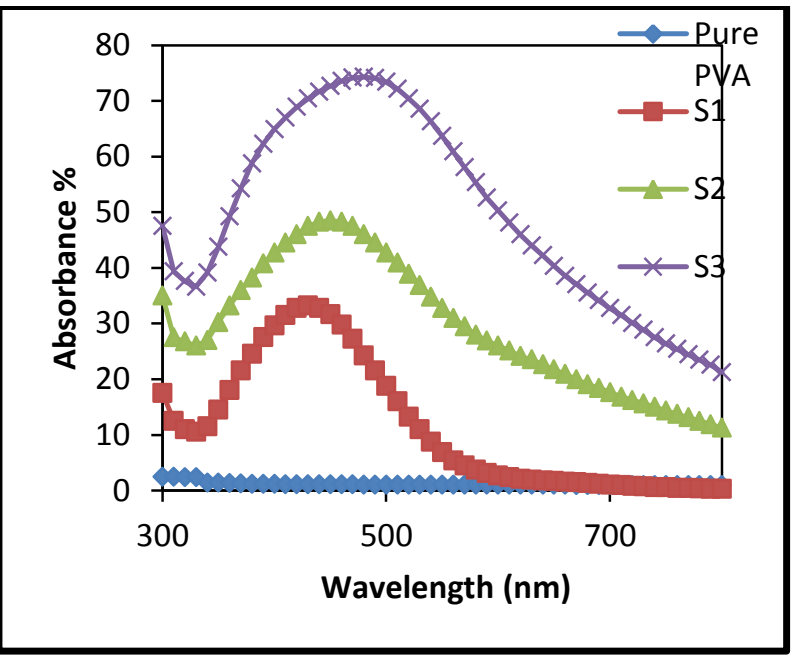

Fig.(1): Absorption spectra as a function of wavelength for pure PVA and Ag/PVA nanocomposites at different concentrations.

The transmittance of pure and Ag/PVA nanocomposites films in the wavelength range $300-800 \mathrm{~nm}$ are shown in Fig.(2). It is clear that the transmittance spectra increases with increasing of wavelength. When the concentration of $\left(\mathrm{AgNO}_{3}\right)$ increases the transmittance decreased for a lower wavelength range. This is due to the fact that there is some absorption in that wavelength range.

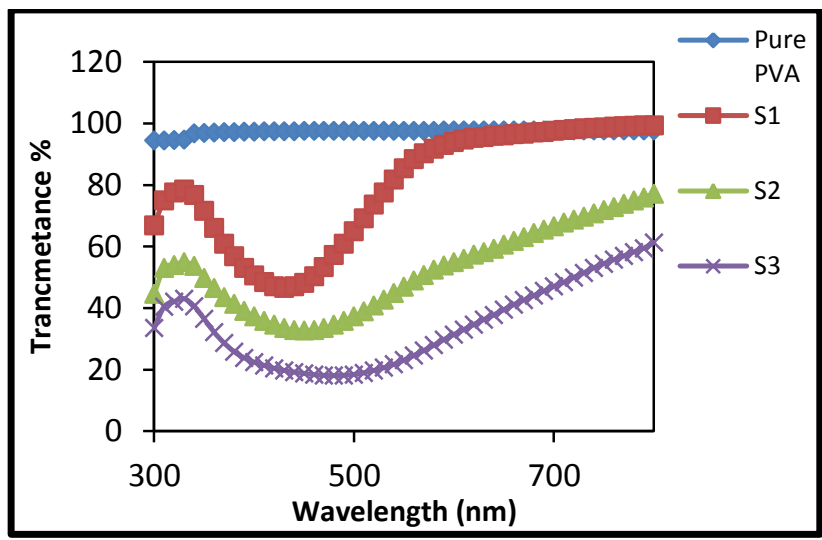

Fig.(2): Transmittance spectra as a function of wavelength for pure $P V A$ and $\mathrm{Ag} / \mathrm{PVA}$ nanocomposites at different concentrations.

Fig.(3). a and $\mathrm{b}$ show the optical absorption coefficients for pure PVA and Ag / PVA nanocomposites films versus photon energies. The presence of metal nanoparticles in the polymer films could be followed by monitoring the plasmon absorption peaks in the absorption spectrum [1,9]. The larger absorption peak appeared in UV range is due to the energy gap of the PVA polymer which decreases owing to increasing the concentration of $\mathrm{Ag}$ nanoparticles in the structure of the films. The position of the absorption edge was determined by extrapolating the linear part of $(\alpha)$ versus (hv) curves to zero absorption value [23].The band edge showed a decrease with increasing concentration of $\mathrm{Ag}$ nanoparticles in PVA matrix. The absorption edge shifts towards higher wavelength, indicating the decrease in the optical band gap for the doped films. Shift of the absorption edge in the UV regions due to changes in the electron hole in the conduction and valence bands. 


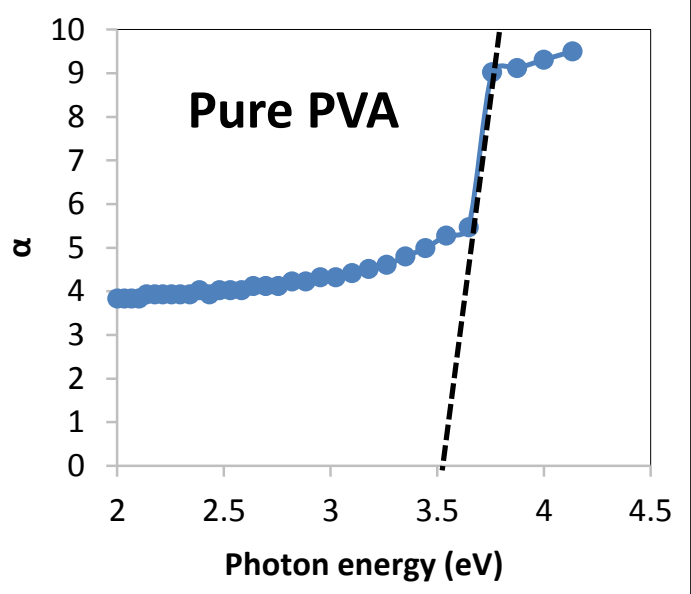

(a)

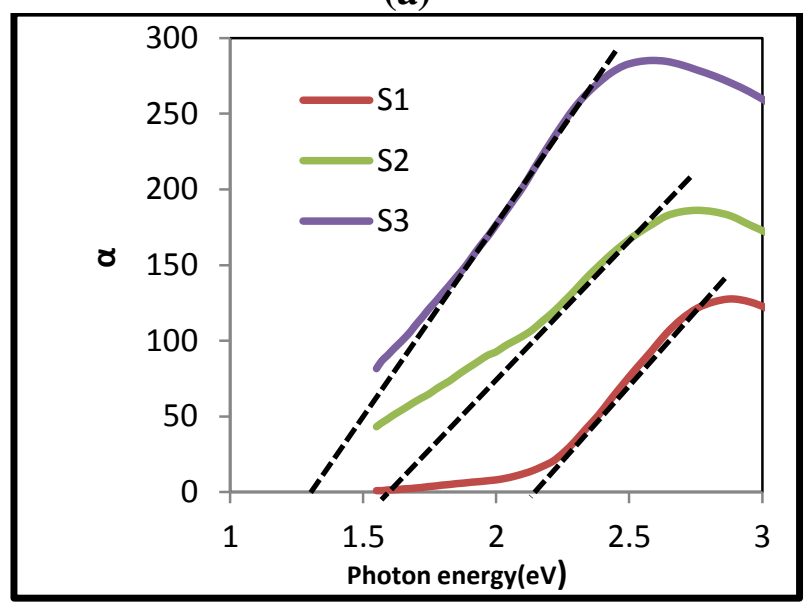

(b)

Fig.(3): Absorption coefficient $\alpha$ spectra as a function of photon energy for pure PVA (a) and Ag/PVA nanocompositesat with different concentrations (b).

Fig.(4) $a$ and $b$ show the variation of energy gap for pure PVA and Ag/PVA nanocomposites films, it can be seen that the values of energy gap decrease with increasing $\mathrm{AgNO}_{3}$ concentration. This decrease due to creation of new levels in the band gap, lead to facilitate the transition of electrons from the valence band to these local levels to the conduction band, consequently the conductivity increases and the band gap decreases [11, 21]. Table (1) summarizes the values of optical band gaps and absorption edges for pure PVA and Ag/PVA nanocomposites films.
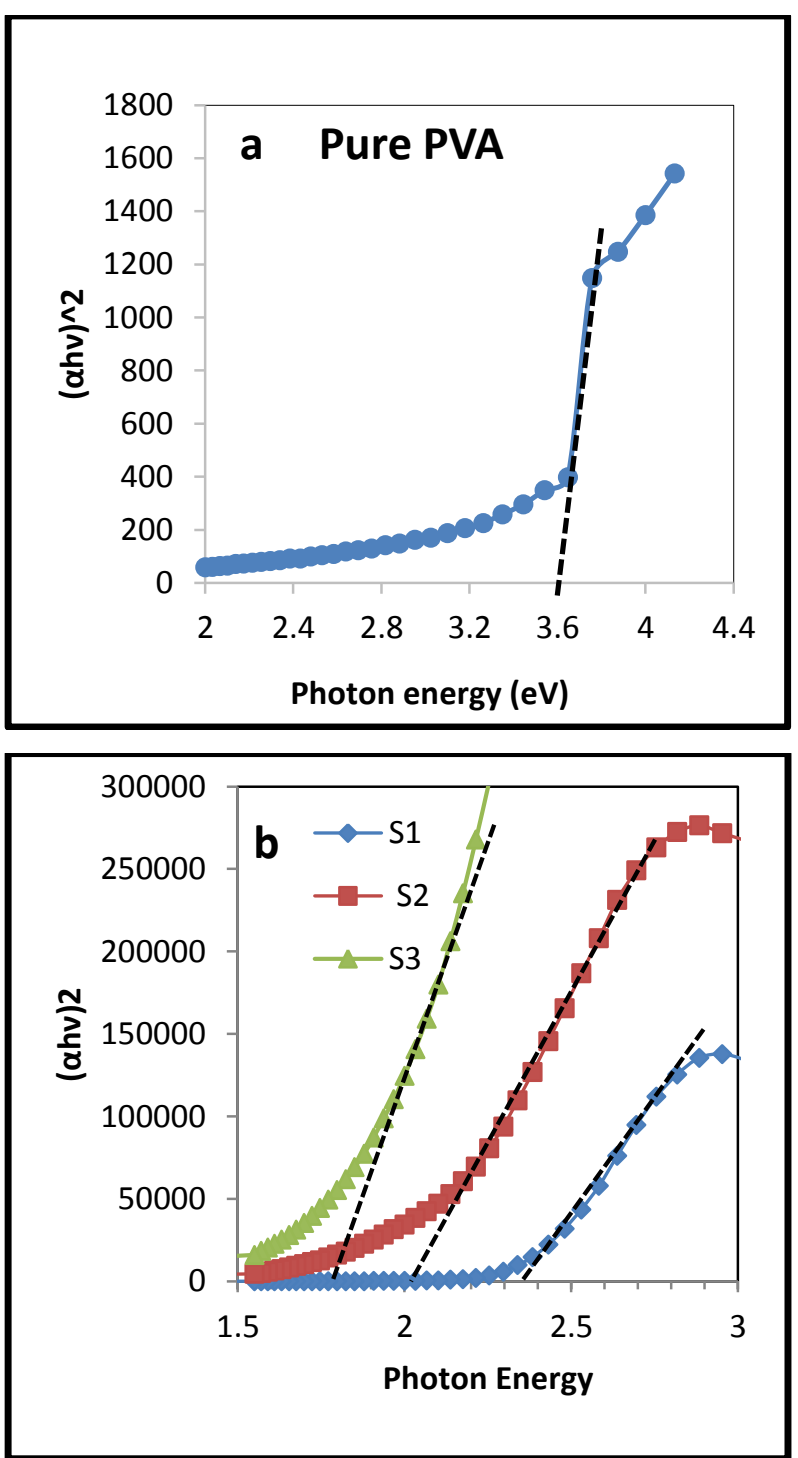

Fig.(4): Optical band gap spectra as a function of photon energy for pure PVA (a) and Ag/PVA nanocomposites at different concentrations (b).

Table (1)

Optical band gaps and absorption edge for pure PVA and Ag/PVA nanocomposites at different concentrations.

\begin{tabular}{|c|c|c|c|}
\hline \multirow[b]{2}{*}{ Sample } & \multirow{2}{*}{$\begin{array}{c}\text { Concentrati } \\
\text { on of } \\
\left(\mathrm{AgNO}_{3}\right) \\
(\mathrm{ml})\end{array}$} & $\begin{array}{c}\text { Optical band } \\
\text { gap }(\mathrm{eV})\end{array}$ & \multirow[b]{2}{*}{$\begin{array}{l}\text { Absorption } \\
\text { edge }(\mathrm{eV})\end{array}$} \\
\hline & & $\begin{array}{c}\text { Direct } \\
\text { allowed } \\
\text { energy band } \\
\text { gap } \\
\end{array}$ & \\
\hline $\begin{array}{l}\text { Pure } \\
\text { PVA }\end{array}$ & 0 & 3.60 & 3.58 \\
\hline $\begin{array}{l}\text { S1 } \\
\end{array}$ & 0.001 & 2.4 & 2.2 \\
\hline S2 & $\begin{array}{c}0.0015 \\
\end{array}$ & $\begin{array}{l}1.9 \\
\end{array}$ & 1.5 \\
\hline S3 & 0.002 & 1.6 & $\begin{array}{c}1.2 \\
\end{array}$ \\
\hline
\end{tabular}

The variation of refractive index $\mathrm{n}$ and extinction coefficient $\mathrm{k}$ with the wavelength are shown in Figs.(5) and (6). The values of $n$ 
and $\mathrm{k}$ were determined from the measured transmittance and reflectance in the wavelength range $300-800 \mathrm{~nm}$. Evaluation of optical constant is considerably important for the applications in the photonic devices, such as switches, filters and optical waveguides. The refractive index $n$ of prepared films shows anomalous dispersion in the spectral range $\lambda<500 \mathrm{~nm}$ and normal dispersion in spectral range $\lambda>500 \mathrm{~nm}$. This anomalous behavior is due to resonance effect between the incident light and the electron's polarization, which leads to the coupling of electrons in the Ag/PVA nanocomposites to the oscillation electromagnetic field. An increase in refractive indices values can be observed with the increase of doping concentrations.

The change of extension coefficient $\mathrm{k}$ as a function of wavelength is shown Fig.(6). It can be seen that the values of $\mathrm{k}$ are decreased at longer wavelengths, showing that the prepared films are more transparent. Higher values of $\mathrm{k}$ observed at high concentration of $\mathrm{AgNO}_{3}$, this is attributed to an increase in the absorption coefficient.

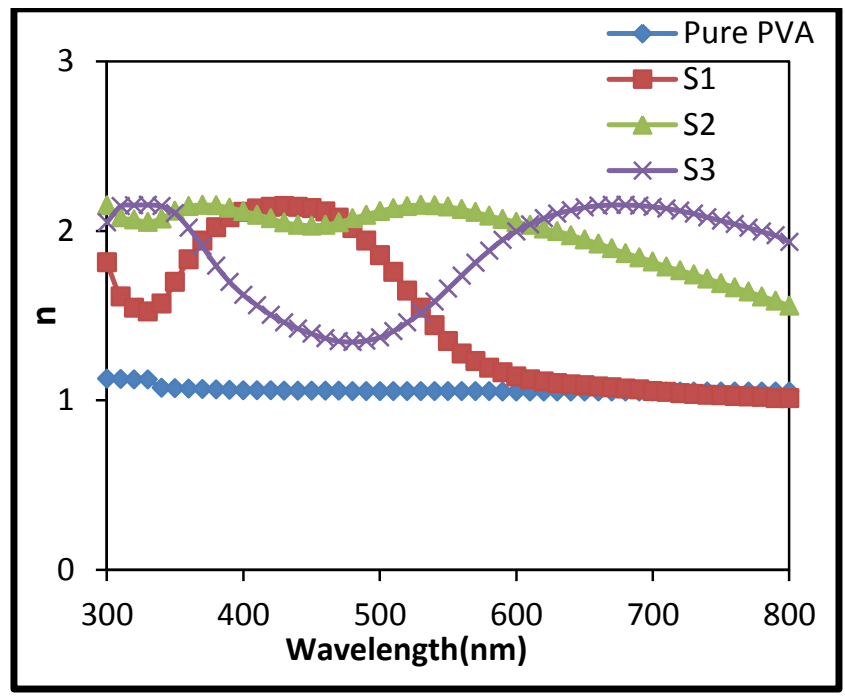

Fig.(5): Refractive index spectra as a function of wavelength for pure PVA and Ag/PVA nanocomposites at different concentrations.

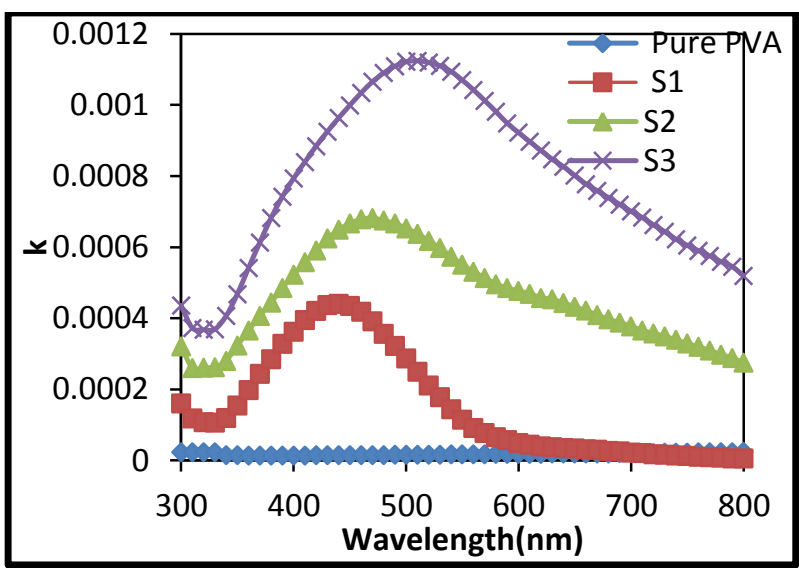

Fig.(6): Extinction coefficient spectra as a function of wavelength for pure PVA and Ag/PVA nanocomposites at different concentrations.

The variation in both real $\left(\varepsilon_{\mathrm{r}}\right)$ and imaginary $\left(\varepsilon_{\mathrm{i}}\right)$ parts of the dielectric constant for different $\left(\mathrm{AgNO}_{3}\right)$ concentrations are shown in Figs.(7) and (8). The complex dielectric function given by equation 6 represents the ability of a material to interact with an electric field and become polarized. The real part $\varepsilon_{\mathrm{r}}$ shows how much it will slow down the speed of light in the material and related to the stored energy; whereas the imaginary part $\varepsilon_{\mathrm{i}}$ related to the absorbed energy from an electric field. The ratio $\frac{\varepsilon_{r}}{\varepsilon_{i}}$ gives the loss factor. Although the behavior of the real and imaginary parts follows the same pattern, the values of the real part are higher than those of the imaginary part. The variation of dielectric constants was due to interactions between photons and charge carriers in the prepared films. The increase of dielectric constant reveals the existence of more energy density of states and these results in an increase of polarization which gives the higher dielectric constant value. 


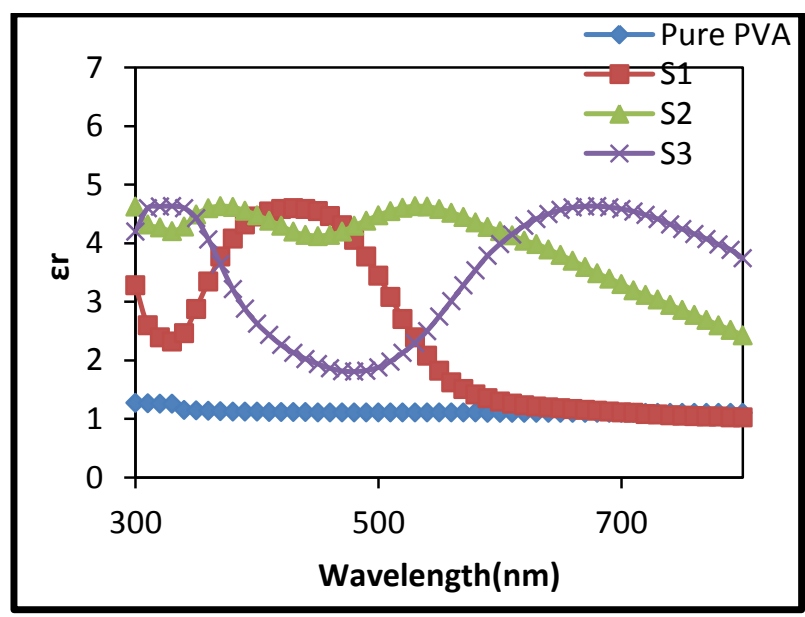

Fig.(7): Real part of dielectric constant as a function of wavelength for pure PVA and Ag/PVA nanocomposites at different concentrations.

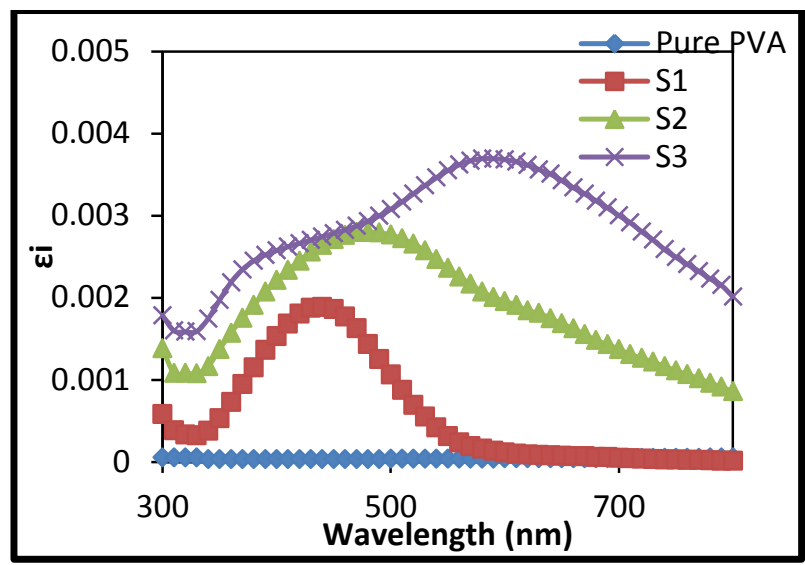

Fig.(8): Imaginary part of dielectric constant as a function of wavelength for pure PVA and Ag/PVA nanocomposites at different concentrations.

Fig.(9) shows the variation of optical conductivity as a function of wavelength. The optical conductivity enhanced upon the addition of $\mathrm{Ag}$ nanoparticles. The large peak appeared in the wavelength region between 400 and $600 \mathrm{~nm}$ for the samples containing nanoparticles are attributed to high absorption coefficient at this spectral region. As can be seen in Fig.(9) the value of optical conductivity increases with increase of the $\mathrm{AgNO}_{3}$ concentration indicating higher number of $\mathrm{Ag}$ nanoparticles generated at higher concentration. This increase due to creation of new local levels in the band gap, lead to facilitate the crossing of electrons from the valence band to these local levels to the conduction band, consequently the band gap decreases and the conductivity increase $[15,24]$.

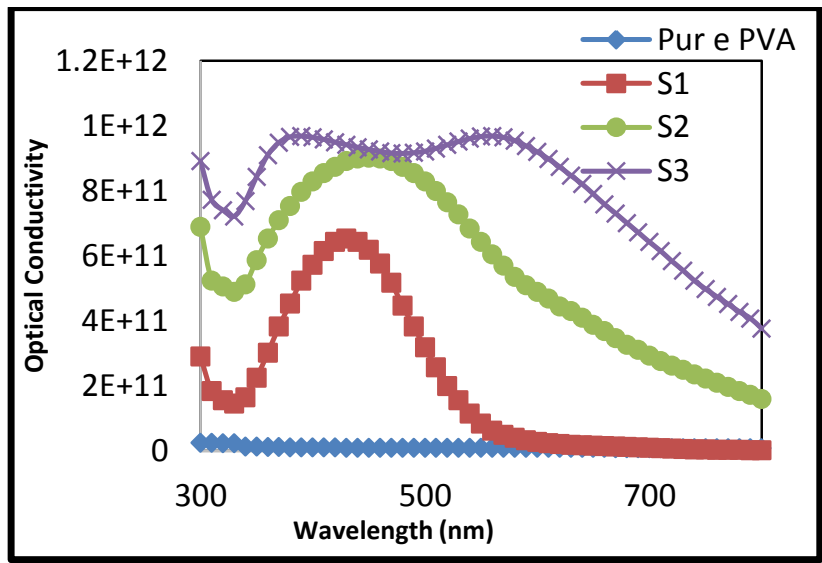

Fig.(9): Optical conductivity spectra as a function of wavelength for pure PVA and Ag/PVA nanocomposites at different concentrations.

\section{Conclusions}

Ag-PVA nanocomposites with different $\left(\mathrm{AgNO}_{3}\right)$ concentrations were prepared by casting technique with thickness (60) $\mu \mathrm{m}$. The UV-VIS spectra of the prepared nanocomposites shows that the optical conductivity increased with the increasing of $\left(\mathrm{AgNO}_{3}\right)$ concentration and the presence of absorption peaks above (400) $\mathrm{nm}$ indicating the formation of silver nanoparticles. Both of Optical absorption edge and optical energy gap decrease with the increasing of $\left(\mathrm{AgNO}_{3}\right)$ concentration.

\section{References}

[1] Gautam A, Ram S. "Preparation and thermomechanical properties of Ag-PVA nanocomposite films" journal of Materials chemistry and physics, 119, 266-271, 2010.

[2] Clémenson S., P., Al-couffe, David L., Espuche E. "Structure and morphology of membranes preparedfrom polyvinyl alcohol and silver nitrate: influence of theannealing treatment and of the film thickness" journal of Desalination, 200, 437-439, 2006.

[3] Ghanipour M. and Dorranian D. "Effect of Ag-Nanoparticles Doped in Polyvinyl Alcohol on the Structural and Optical Properties of PVA Films" Journal of NanomaterialsVol.2013, Article ID 897043, 10 pages. 
[4] Ananth N., S., Umapathy J. Sophia , Mathavan T., Mangalaraj D. "On the optical and thermal properties of in situ/ex situ reduced Ag NP's/PVA composites and its role as a simple SPR-based protein sensor" Appl. Nanosci., 1,87-96, 2011.

[5] Rong Zeng, Min Zhi Rong, Ming Qiu Zhang, Hai Chun Liang, Han Min Zeng, "Laser ablation of polymer-based silver nanocomposites" Applied Surface Science 187 ,239-247, 2002.

[6] Maribel G, Jean Dille, Stephan Godet "Synthesis of Silver nanoparticles by chemical reduction method and their antibacterial activity", International Journal of chemical and Bimolecular Engineering, 2(3), 2009.

[7] Kensuke A., Shodo Takei, Minoru M., Akihiko K., Shigehito D., Shinji T., Minoru Fujii, Shinji Hayashi, Keiichi Yamamoto "Preparation and characterization of polymer thin films containing silver and silver sulfide nanoparticles", Thin Solid Films 359, 55-60, 2000.

[8] Iravani S., Korbekandi H., Mirmohammadi S.V., and Zolfaghari B. "Synthesis of silver nanoparticles: chemical, physical and biological methods", Res Pharm Sci., 9(6): 385-406, 2014.

[9] Yunus W., Kharazmi A., Saion E., ShahmiriM., Tamchek N., "Synthesis, Characterization and nonlinear Optical properties of Silver/ PVA nanocomposites", Journal Europ. Opt. Soc. Rap.Public. 7, 12040, 2012.

[10] Aseel S. Jasim, "Preparation and Optical Characterization of Polymer Composites Reinforced by Natural Materials" Journal of Al-Nahrain University, 19 (1), 91-97, March, 2016.

[11] Mansour A.F., Mansour S.F. and Abdo M.A., "Improvement structural and optical properties of $\mathrm{ZnO} / \mathrm{PVA}$ Nanocomposites", journal of Applied physics (IOSR), 7, 6069, 2015.

[12] Ibrahim R. Agool, Ahmed H., "preparation of (PVA-PEG-PVP-MgO, $\mathrm{CoO})$ Nanocomposites and study their optical properties", International Journal of science and Research(IJSR),2319-7064, 2012.

[13] Farag A.M., Yahia I.S., Yakuphanoglu F., Kandaz M., Farooq W.A. "Optical properties and the dispersion parameters of new zinc Phthalocyaninebenzofuran derivative prepared by non-vacuum spin coating technique, Optics Communications, 3122-3127, 2012.

[14] Shehap A.M., Dana S. Akil, "Structural and optical properties of $\mathrm{TiO} 2$ nanoparticles/PVA for different composites thin films "Int. J. Nanoelectronics and Materials 9, 17-36, 2016.

[15] Sami S. Chiad, Saad F. Oboudi, Khalid H. Abaas, Nadir F. Habubi "characterization of Silver/Poly (Vinyl Alcohol)(Ag/PVA) Films prepared by casting Technique", Iraqi J. of polymers, 16(2), 10-18,2012.

[16] Dresselhaus M. S., "Optical Properties of Solids", Solid State Physics Part II, 6, 2001.

[17] Hodgson J. N., “Optical Absorption and Dispersion in Solids", Chapman \& Hall, London, UK, 1971.

[18] Caglar Y., S. Ilican, and M. Caglar, "Single-oscillator model and determination of optical constants of spray pyrolyzedamorphous $\mathrm{SnO}_{2}$ thin films," European Physical Journal B, 58, (3), 251256, 2007.

[19] Saleh H. H., El-Hadedy D. E., Meligi G.A. and Afify T. A. "Synthesis, Characterization and Antibacterial Activity of Ag/PVA nanocomposite", Journal of Scientific Research, 5(1), 151-160, 2013.

[20] Rajib S., "Synthesis and characterization of the Silver $(\mathrm{Ag}) /$ Polyvinyle Alchohol (PVA) nanocomposites and their Application in Electronics and Photonics, Ph.D. Thesis Faculty of Technology, Gauhati University, India 2012.

[21] Abdelrazak E.M., Abdelghany A.M., Tarabih A.E., "Characterization and Physical Properties of Silver/ PVA nanocomposite", Research Journal of Pharmaceutical, Biological and Chemical Science, 3(4), 448, 2012 
[22] Khanna P. K., Narendra S., Shobhit C. and Kasiiswanath A., "Synthesis of $\mathrm{Ag} /$ polyaniline nanocomposite via an in situ photo-redox mechanism", Mater. Chem. and Phys., 92, 214-219, 2005

[23] Devi C. U., Sharma A. K., and Rao V., "Electrical and optical properties of pure and silver nitrate-doped polyvinyl alcohol films", Materials Letters, 56(3), 167-174, 2002.

[24] Yakuphanoglu F., Sekerci M., Ozturk O.F., "The Determination of the Optical Constants of $\mathrm{Cu}$ (II) Compound having 1Chloro-2-3 Cyclohexylidinepropane Thin Films" Optics communication", 239, (2004), 275-280. 